\title{
Differential response of tellimagrandin II and total bioactive hydrolysable tannins in an aquatic angiosperm to changes in light and nitrogen
}

\author{
Elisabeth M. Gross
}

\begin{abstract}
The submerged freshwater angiosperm Myriophyllum spicatum produces high amounts of polyphenols, especially gallotannins, with broad biological activity against insect herbivores, algae, cyanobacteria and heterotrophic bacteria. To test whether resource availability explains the intraspecific variability of these hydrolysable tannins, the impact of light and nitrogen on the production and release of total polyphenols and tellimagrandin II, the major allelochemical present in $M$. spicatum was investigated. Axenic cultures grown in a controlled environment allowed to exclude any effects of herbivores, epiphytes or pathogens on phenolic compounds. Light had a strong positive effect both on tissue-bound and exuded polyphenolic compounds. Nitrogen availability neither influenced the total content of tissue-bound polyphenols nor the exudation of phenolic compounds. In contrast, at low nitrogen and low light availability tissue concentrations of the major polyphenol tellimagrandin II increased. These findings are important considering the allelochemical activity of $M$. spicatum polyphenols, especially tellimagrandin II. The results are assessed in the context of the recent debate on the validity of the carbon-nutrient balance hypothesis and possible other models.
\end{abstract}

E. M. Gross, Limnological Institute, Univ. of Konstanz, PO Box M659, DE-78457 Konstanz, Germany (elisabeth.gross@uni-konstanz.de).

Factors controlling the intraspecific variability of defensive compounds in higher plants have been explored extensively. In the past, primarily two models have been put forward to explain this variability: The carbon-nutrient balance hypothesis $(\mathrm{CNBH})$ predicts that the concentration of defensive compounds is proportional to the availability of resources such as nitrogen or light (Bryant et al. 1983). The evolutionary response of nutrient-limited plants to herbivory would be to invest in constitutive carbon-based secondary metabolites. For the main part of their seminal paper, Bryant et al. (1983) focused on woody boreal plants and herbivory by mammals, yet they concluded that the carbon-nutrient balance of all plants must play an important role for plant defence in general. In contrast, the optimal defence model (ODM; Rhoades 1979, Kar- ban and Myers 1989) predicts that plants adjust the amount of defensive compounds in their tissue based on the danger of being grazed upon. These basic models have been modified and adjusted, leading to several new hypotheses, and culminating recently in the proclaimed demise of the CNBH (Hamilton et al. 2001, Koricheva 2002, Lerdau and Coley 2002, Nitao et al. 2002). The main criticism of the $\mathrm{CNBH}$ focuses on its restricted use to phenolic compounds originating via phenylalanine-ammonium, thus excluding hydrolysable tannins that only occasionally originate via phenylalanine but mostly originate directly from shikimate (Seigler 1998). Others pointed out that individual defensive compounds may not follow the CNBH (Koricheva et al. 1998, Koricheva 2002) but are rather regulated by demand, i.e. defence reactions. Bryant et al. (1987) were 
the first to consider the importance of individual compounds as defensive compounds in the context of the $\mathrm{CNBH}$. They pointed out that nutrients and light may directly influence biosynthesis and regulation of secondary metabolism at the enzyme level, and that this may explain varying responses in different plants.

So far, the majority of studies on the $\mathrm{CNBH}$ or alternative hypotheses have emerged from terrestrial studies (Koricheva et al. 1998), supplemented by a few studies on phlorotannin-containing marine macroalgae (Pavia and Brock 2000, Van Alstyne and Pelletreau 2000). Apparently, no study has ever tested the CNBH or other hypotheses on defensive compounds in freshwater higher plants. This is surprising, since aquatic angiosperms are secondarily aquatic, i.e. have terrestrial ancestors, and as a consequence it is likely that they have developed similar chemical defences to their relatives on land. Moreover, submersed macrophytes can be nitrogen limited (Sytsma and Anderson 1993b), and are usually subjected to severe shading (Sand-Jensen 1990).

The aquatic dicotyle Myriophyllum spicatum L. (Haloragaceae), also called milfoil, is a highly suitable model organism to test the impact of resources on phenolic compounds due to its high content of hydrolysable tannins (Gross et al. 1996). It is very competitive, especially due to its fast growth, canopy formation and vigorous vegetative spread. In contrast to other submersed macrophytes, $M$. spicatum and other members of the family of the Haloragaceae contain about one order of magnitude higher concentrations of phenolic compounds (Smolders et al. 2000, Choi et al. 2002). In general, submersed living aquatic angiosperms are considered to contain less phenolic compounds than floating-leaved or emergent macrophytes (Smolders et al. 2000). M. spicatum contains 7 to $25 \%$ hydrolysable polyphenols based on dry mass. Among them, tellimagrandin II is the major polyphenol present in concentrations of one to five percent of dry mass (Gross et al. 1996, E. M. Gross, unpubl.). Alkaloids (Ostrofsky and Zettler 1986) and cyanogenic glucosides (Fikenscher and Hegnauer 1981) are also present in $M$. spicatum, but these nitrogenbased secondary metabolites are present in concentrations less than $0.1 \%$ of dry mass and have not been associated with biological activity so far.

Myriophyllum spicatum polyphenols exhibit wide allelochemical activity: The growth of aquatic herbivorous moth larvae (Acentria ephemerella Dennis \& Schiffermüller, Lepidoptera: Pyralidae) is reduced when feeding on the polyphenol-rich $M$. spicatum compared to the polyphenol-free Potamogeton perfoliatus L. (Choi et al. 2002). Polyphenols from M. spicatum also inhibited gut bacteria isolated from Acentria (Walenciak et al. 2002). In general, tannins are considered effective feeding deterrents, although Schultz et al. (1992) proposed that tannin interference with herbivores is essentially based on their antimicrobial activity. Furthermore, tellimagrandin II and other hydrolysable tannins in milfoil are allelopathically active and inhibit algal or cyanobacterial growth, mainly due to their interference with exoenzymes and photosynthesis (Gross et al. 1996, Leu et al. 2002).

Considering the wide biological activity of milfoil polyphenols, the question remains whether the intraspecific variability of these allelochemicals follows the predictions of the CNBH. In situ, M. spicatum growth can be subjected to both nitrogen and light limitation (Gerloff and Krombholz 1966, Madsen et al. 1991, Abernethy et al. 1996), or it can be exposed to high light levels as when forming canopies at the water surface (Barko and Smart 1981, Madsen et al. 1991). Light availability for submersed macrophytes is determined by growth architecture and the depth of growth in the lake, and even more so by the shading through competing photoautotrophs. According to the $\mathrm{CNBH}$, $M$. spicatum should respond to lower light levels with a decrease in phenolic compounds. This, however, would weaken allelopathic interactions with phytoplankton and epiphytes.

Primarily, this study was designed to test if and how light and nitrogen availability would influence total phenolic compounds and the major allelochemical tellimagrandin II in M. spicatum. The null hypothesis tests whether this aquatic angiosperm responds predominantly to abiotic stressors, thus confirming the $\mathrm{CNBH}$. This study investigated both the total concentration of phenolic compounds, the exudation of phenolic compounds and the concentration of tellimagrandin II in plant tissue, to answer the question whether the pool of phenolic compounds is regulated in the same manner as individual bioactive compounds.

\section{Material and methods}

\section{Axenic Myriophyllum spicatum}

Shoots of $M$. spicatum were collected by snorkelling in Schöhsee, Northern Germany $\left(54^{\circ} 10^{\prime} \mathrm{N}, 10^{\circ} 27^{\prime} \mathrm{E}\right)$, at a water depth of 2 to 4 meters. Plants were freed from debris and grown in an aquarium on pebbles with $5 \mathrm{~cm}$ tap water for two weeks. This procedure yielded aerial shoots, which are easier to use in surface sterilization. Axenic shoots were produced according to Kane and Gilman 1991 and Kane et al. 1991. All leaves on apical shoot sections of two or three nodes length were removed, and the stems were surface-sterilized in $1.05 \%$ (v/v) sodiumhypochlorite and $0.01 \%(\mathrm{v} / \mathrm{v})$ Tween-20. Bleached stem sections were rinsed three times in ultrapure water and transferred to medium A. Axenity of cultures was tested regularly. The use of axenic cultures allowed a controlled cultivation under different resource levels, and prevented interference by epiphytes, herbivores and pathogens. 
Medium A is a modified Murashige and Skoog (1962) medium with inorganic salts used in halfstrength and supplemented with $0.56 \mathrm{mM}$ myo-inositol, $1.2 \mu \mathrm{M}$ thiamin $-\mathrm{HCl}, 87.6 \mathrm{mM}$ sucrose and $4.9 \mu \mathrm{M}$ 6-( $\tau, \tau$-dimethylallylamino)-purin $\quad(2 \mathrm{iP} ; \quad$ Sigma $) . \quad 2 \mathrm{iP}$ serves as a cytokine and promotes cell division and new axial shoot formation in $M$. spicatum. Culture conditions were $20^{\circ} \mathrm{C}\left( \pm 1^{\circ} \mathrm{C}\right)$ and $100 \mu \mathrm{mol}$ photons PAR $\mathrm{m}^{-2} \mathrm{~s}^{-1}$ at 14:10 L:D (OSRAM L36W/72 Biolux, 120 $\mathrm{cm}$ length). Medium A is used in our laboratory for stock cultures of $M$. spicatum, because of the vigorous growth of shoot fragments. However, this medium contains nutrient concentrations too high compared with lake water and also organic additives that can disturb analytical procedures. Therefore, mineral medium B (MMB) suitable for submersed macrophytes, especially $M$. spicatum, was used for the experiments (Gerloff and Krombholz 1966, Gerloff 1975). Trace elements were used as in medium A. MMB was supplemented after autoclaving with sterile filtered $\mathrm{NaHCO}_{3}(200 \mu \mathrm{M}$ final concentration). Cultures were moved to MMB two weeks before the experiment started to allow plants to adjust to the ion strength of this medium.

\section{Experimental set up}

The impact of light and nitrogen availability on phenolic compounds in $M$. spicatum was tested in a factorial design with two light and four nitrogen levels. Each replicate received three shoots of $M$. spicatum $(5 \mathrm{~cm}$ long) in $100 \mathrm{ml} \mathrm{MMB}$. The starting weight (dry mass/ $\mathrm{dm}$ ) was determined with 10 samples of three shoots each (material not used in experiment). Cultures were maintained sterile in $300 \mathrm{ml}$ Erlenmeyer flasks and incubated in a ventilated phototron at $20^{\circ} \mathrm{C}$ and either low $\left(150 \mu \mathrm{M}\right.$ photons PAR $\left.\mathrm{m}^{-2} \mathrm{~s}^{-1}\right)$ or high $(650 \mu \mathrm{M}$ photons PAR $\mathrm{m}^{-2} \mathrm{~s}^{-1}$ ) light. Nitrogen concentrations were modified from the normal concentration of 2.4 $\mathrm{mM} \mathrm{N}-\mathrm{NO}_{3}$ in $\mathrm{MMB}$ to final concentrations of 0.6 , $1.2,2.4$ or $4.8 \mathrm{mM} \mathrm{N}-\mathrm{NO}_{3}$ in the four nutrient treatments, yielding molar $\mathrm{N}: \mathrm{P}$ ratios of $3: 1,6: 1,12: 1$ and 24:1. Cultures were grown for eight weeks, and the medium was changed every second week to prevent nutrient limitation.

\section{Chemical analysis}

At the end of the experiment, milfoil shoots from each flask were washed with tap water and blotted dry. Wet weight of the plants was determined and then put in liquid nitrogen, freeze-dried, weighed $(\mathrm{dm})$, and finely ground for further processing. The relative growth rate was calculated as $\mathrm{RGR}=\left(\begin{array}{ll}\ln \mathrm{dm}_{\text {final }}-\ln \mathrm{dm}_{\text {initial }}\end{array}\right)$ day $^{-1}$. Total phenolic compounds in the tissue $\left(\mathrm{TPC}_{\mathrm{t}}\right)$ were determined with the Folin-Ciocalteau assay using tannic acid (Sigma) as standard (Gross et al. 1996). Results are expressed as tannic acid equivalents (TAE) based on dry mass. Tellimagrandin II (T-II) was quantified using HPLC (Gross et al. 1996). The carbon and nitrogen content of the tissue was determined with an Elementar Analysator NCS 2500 (CE Instruments/ Thermoquest) using atropine sulfate as standard.

The excretion of phenolic compounds $\left(\mathrm{TPC}_{\mathrm{e}}\right)$ and other organic compounds (total organic carbon/TOC) were measured only at the end of the experiment in the spent medium ( 2 weeks old). The Folin-Ciocalteau assay was directly performed with medium. Controls used medium without plants. The $\mathrm{TPC}_{\mathrm{e}}$ was expressed as TAE per gram dm. T-II exuded to the medium can only be detected shortly after plants are moved to fresh medium, because this compound undergoes metabolization and was therefore not measured in the exudate (see Gross and Sütfeld 1994). TOC in the medium was determined with a Shimadzu TOC 5000A-PC analyser and $\mathrm{KHCO}_{3}$ as standard.

\section{Statistical analysis}

Data were analysed with Statistica Vers. 5.5, using the GLM procedure. Effects of light and nitrate on measured variables were tested using 2-way-ANOVA, effects of $\mathrm{C}: \mathrm{N}$ ratio on dependent variables was tested with ANCOVA and light as covariate. Arcsine transformations were performed with all proportional data. All data were tested for normal distribution (K-S-test) and variance homogeneity (Levene's test). $\mathrm{TPC}_{\mathrm{e}}$ and TOC (both medium) were $\ln +0.1$ transformed. This yielded equal variance for $\mathrm{TPC}_{\mathrm{e}}$ but not for TOC. Since the TOC data exhibit a large difference between the two light levels, this is not considered crucial. Differences between the four nitrate levels were tested with Tukey's HSD test.

\section{Results}

Myriophyllum spicatum shoots grew during the experiment from $15 \pm 4 \mathrm{mg} \mathrm{dm}$ to $119 \pm 23 \mathrm{mg} \mathrm{dm}$ per flask (mean $\pm \mathrm{SD} ; \mathrm{n}=24$ ), with no significant difference between treatments (Table 1 ). This yielded a mean relative growth rate $(\mathrm{RGR})$ of $0.037 \pm 0.002 \mathrm{day}^{-1}$. The incubation medium turned slightly yellowish during the two-week incubation intervals, indicating the exudation of phenolic compounds.

\section{Light}

Increasing the light intensity significantly affected both tissue nitrogen and the phenolic content in axenic $M$. spicatum shoots (Table 1, Fig. 1). The carbon content 
Table 1. Results of two-way ANOVAs with light and nitrogen as factors for $M$. spicatum plant chemistry and released compounds. Two light and four nitrogen levels were tested in a $2 \times 4$ factorial design with $n=3$ per treatment. Light $\mathrm{df}=1$, nitrogen $\mathrm{df}=3$, light $\times$ nitrogen $\mathrm{df}=3$. RGR: relative growth rate; $\mathrm{TPC}_{\mathrm{t}}$ : total phenolic compounds in plant tissue; T-II: tellimagrandin II. TOC: dissolved organic compounds in medium; $\mathrm{TPC}_{\mathrm{e}}$ : phenolic compounds in cultivation medium.

\begin{tabular}{|c|c|c|c|c|c|c|}
\hline \multirow[t]{2}{*}{ Factor } & \multicolumn{2}{|l|}{ Light } & \multicolumn{2}{|c|}{ Nitrogen } & \multicolumn{2}{|c|}{ Light $\times$ nitrogen } \\
\hline & $\mathrm{F}$ & $\mathrm{p}$ & $\mathrm{F}$ & $\mathrm{p}$ & $\mathrm{F}$ & $\mathrm{p}$ \\
\hline plant growth (RGR) & 2.6 & 0.13 & 1.8 & 0.20 & 0.6 & 0.61 \\
\hline $\begin{array}{l}\text { Tissue } \\
\% \text { carbon } \\
\% \text { nitrogen } \\
\text { C:N ratio } \\
\text { TPC } \\
\text { T-II } \\
\% \mathrm{~T}-\mathrm{II} \text { on } \mathrm{TPC}_{\mathrm{t}}\end{array}$ & $\begin{array}{r}0.89 \\
30.28 \\
20.88 \\
42.88 \\
4.71 \\
14.66\end{array}$ & $\begin{array}{c}0.36 \\
<0.0001 \\
0.0003 \\
<0.0001 \\
0.045 \\
0.0015\end{array}$ & $\begin{array}{r}1.42 \\
31.72 \\
14.45 \\
0.38 \\
10.48 \\
6.94\end{array}$ & $\begin{aligned} & 0.28 \\
< & 0.0001 \\
< & 0.0001 \\
& 0.77 \\
& 0.0005 \\
& 0.0033\end{aligned}$ & $\begin{array}{l}0.73 \\
0.39 \\
0.27 \\
0.35 \\
0.54 \\
0.20\end{array}$ & $\begin{array}{l}0.55 \\
0.76 \\
0.84 \\
0.79 \\
0.66 \\
0.90\end{array}$ \\
\hline $\begin{array}{l}\text { Medium } \\
\text { TOC } \\
\text { TPC }_{\mathrm{e}} \\
{ }_{0} \mathrm{TPC}_{\mathrm{e}} \text { on } \mathrm{TOC}\end{array}$ & $\begin{array}{r}93.87 \\
6.78 \\
6.11\end{array}$ & $\begin{array}{c}<0.0001 \\
0.02 \\
0.0251\end{array}$ & $\begin{array}{l}1.42 \\
0.39 \\
2.24\end{array}$ & $\begin{array}{l}0.27 \\
0.76 \\
0.12\end{array}$ & $\begin{array}{l}0.24 \\
0.15 \\
0.08\end{array}$ & $\begin{array}{l}0.87 \\
0.93 \\
0.97\end{array}$ \\
\hline
\end{tabular}

stayed constant in all treatments (Fig. 1A, Table 1). At high light intensity, the tissue nitrogen content increased by $11-15 \%$ compared to low light (Fig. 1B). This resulted in significantly lower $\mathrm{C}: \mathrm{N}$ ratios at high light (Fig. 1C).

The total phenolic compounds in $M$. spicatum shoots $\left(\mathrm{TPC}_{\mathrm{t}}\right)$ increased by $22-34 \%$ in high light (Fig. 1D). In contrast, high light resulted in a lower content of tellimagrandin II (T-II) in shoots $(p=0.045)$, especially at high nitrate levels where T-II dropped almost by half (Fig. 1E). At low light, the proportion of T-II on $\mathrm{TPC}_{\mathrm{t}}$ increased by $33-140 \%$ compared to the respective high light treatments (Fig. 1F).

Light had also a strong impact on organic compounds exuded by $M$. spicatum shoots (TOC, Table 1 , Fig. 2). At high light, $120-180 \%$ more TOC was found in the spent medium (Fig. 2A). Total phenolic compounds exuded $\left(\mathrm{TPC}_{\mathrm{e}}\right)$ increased by $60-140 \%$ compared to low light cultures (Fig. 2B). However, the proportion of $\mathrm{TPC}_{\mathrm{e}}$ on $\mathrm{TOC}$ was higher in low light compared to high light conditions (increase by $24-44 \%$, $\mathrm{p}=0.0251$ ).

\section{Nitrogen}

Nitrogen concentrations in axenic $M$. spicatum shoots increased with the amount of nitrate offered in the culture medium up to $2.4 \mathrm{mM}$, and then stayed constant (Table 1, Fig. 1B). Nitrogen availability also influenced the $\mathrm{C}: \mathrm{N}$ ratio and T-II content (Fig. 1C, E), but not the $\mathrm{TPC}_{t}$ (Fig. 1D). Significant differences were found always between the two lowest $(0.6,1.2 \mathrm{mM}$ $\left.\mathrm{N}-\mathrm{NO}_{3}\right)$ and the two highest $\left(2.4,4.8 \mathrm{mM} \mathrm{N}-\mathrm{NO}_{3}\right)$ nitrate concentrations offered (Tukey's HSD, $\mathrm{p}<0.05$ ). T-II declined from approximately $10 \mu \mathrm{g} \mathrm{mg}^{-1} \mathrm{dm}$ at low nitrate availability to $4-7 \mu \mathrm{g} \mathrm{mg}^{-1}$ at high nitrate levels (Fig. 1E).
Nitrate availability had no effect on exuded compounds, neither on TOC nor on $\mathrm{TPC}_{\mathrm{e}}$ (Fig. 2). None of the tissue or medium variables analysed exhibited any interaction effect between light and nitrogen (Table 1).

\section{Impact of C:N ratio on phenolic compounds in M. spicatum}

Finally, both $\mathrm{TPC}_{\mathrm{t}}$ and T-II were analysed as a function of the M. spicatum tissue C:N molar ratio (Fig. 3), since this parameter reflects the plants response to the combined availability of light and nitrate. Data were analysed with ANCOVA using light as a covariate and subsequent regression analyses. The light availability strongly influenced the $\mathrm{TPC}_{\mathrm{t}}$ levels (light $\mathrm{df}=1, \mathrm{~F}=$ $51.8, \mathrm{p}<0.0001 ; \mathrm{C}: \mathrm{N}$ df $=1, \mathrm{~F}=2.4, \mathrm{p}=0.13)$, therefore both light levels were analysed separately. At low light, $\mathrm{TPC}_{\mathrm{t}}$ increased with higher $\mathrm{C}: \mathrm{N}$ ratios; the regression was marginally significant $\left(\mathrm{TPC}_{\mathrm{t}}=(-59.8 \pm\right.$ $22.8)+(2.8 \pm 1.5) \times \mathrm{C}: \mathrm{N} ; \quad$ mean $\pm \mathrm{SE} ; \quad \mathrm{r}_{\mathrm{adj}}^{2}=0.19$, $\mathrm{p}=0.086$ ). For high light no correlation was found $\left(r_{\mathrm{adj}}^{2}=0.0, \mathrm{p}=0.65\right)$.

In contrast, light level had no effect whereas the $\mathrm{C}: \mathrm{N}$ ratio strongly influenced $\mathrm{T}$-II concentrations (light $\mathrm{df}=$ $1, \mathrm{~F}=0.14, \mathrm{p}>0.7 ; \mathrm{C}: \mathrm{N} \mathrm{df}=1, \mathrm{~F}=15.1, \mathrm{p}<0.001)$. Data from both light levels were therefore pooled to calculate the relation between $\mathrm{T}-\mathrm{II}$ and $\mathrm{C}: \mathrm{N}$ ratio. The $\mathrm{T}-\mathrm{II}$ content increased with higher $\mathrm{C}: \mathrm{N}$ ratios $(\mathrm{T}-\mathrm{II}=$ $(-7.7 \pm 3.6)+(1.1 \pm 0.3) \times \mathrm{C}: \mathrm{N} ; \quad \mathrm{r}_{\mathrm{adj}}^{2}=0.44, \quad \mathrm{p}<$ $0.0005)$.

\section{Discussion}

Environmental factors influenced carbon-based secondary compounds (CBSC) in the aquatic angiosperm Myriophyllum spicatum. The intraspecific variability of 


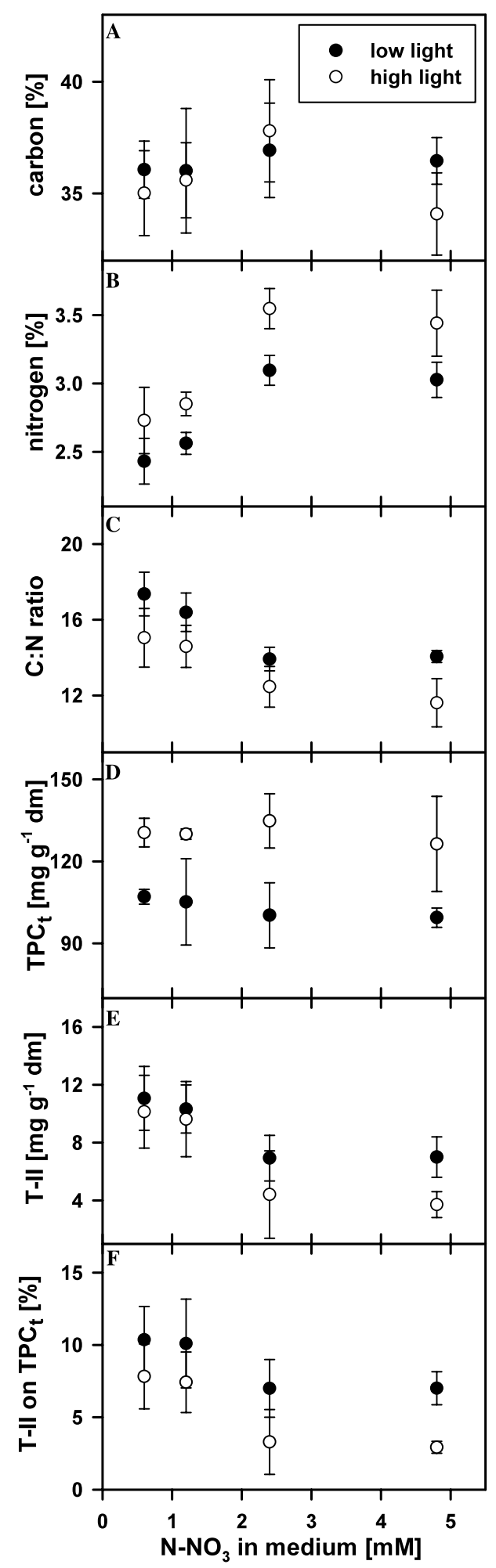

Fig. 1. Impact of light and nitrogen on tissue concentrations of nitrogen and phenolic compounds in axenic Myriophyllum spicatum. Data represent mean $\mathrm{SD}, \mathrm{n}=3$ per treatment $\mathrm{TPC}_{\mathrm{t}}$ : total phenolic compounds in plant tissue; T-II: tellimagrandin II.

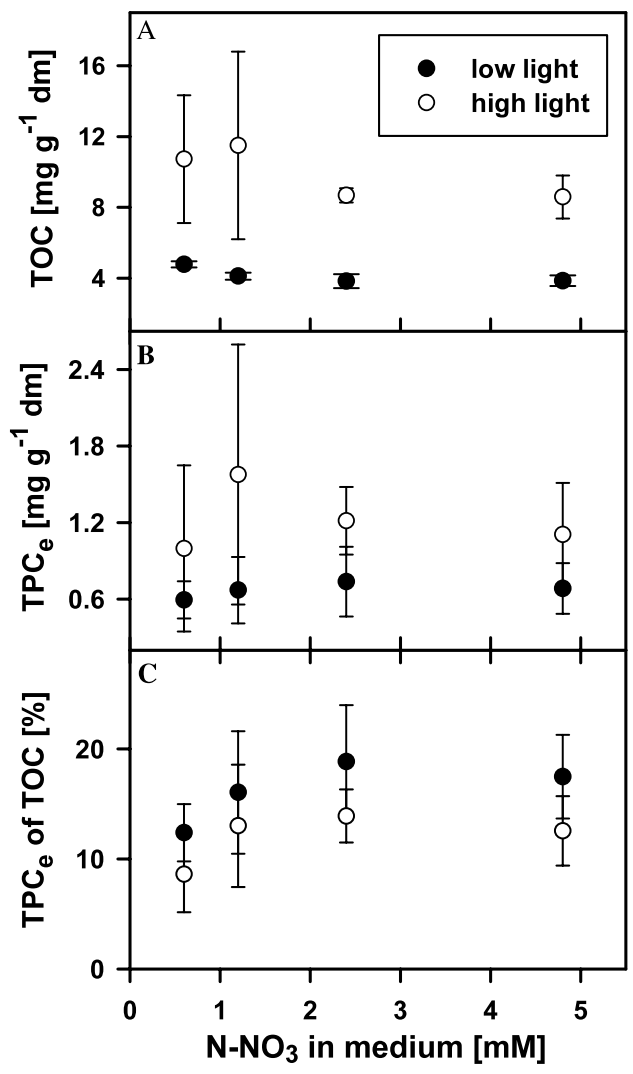

Fig. 2. Impact of light and nitrogen on the exudation of phenolic compounds $\left(\mathrm{TPC}_{\mathrm{e}}\right.$ ) and other organic compounds (TOC) in liquid cultures of axenic $M$. spicatum. Data represent mean $\pm \mathrm{SD}, \mathrm{n}=3$ per treatment. TOC: dissolved organic compounds in medium; TPC $_{\mathrm{e}}$ : phenolic compounds in cultivation medium.

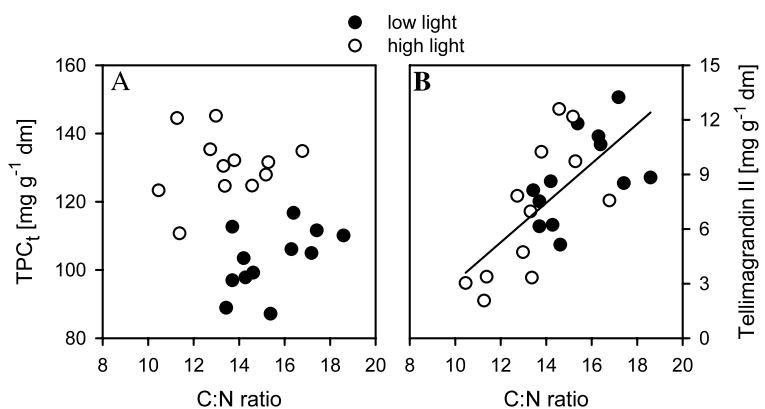

Fig. 3. Relationship between C:N ratio and polyphenols in $M$. spicatum tissue. (A) Relation between total phenolic compounds in plant tissue $\left(\mathrm{TPC}_{\mathrm{t}}\right.$ ) and $\mathrm{C}: \mathrm{N}$ ratio. (B) Relation between tellimagrandin II in plant tissue (T-II) and C:N ratio.

the total phenolic compounds and the major allelochemical tellimagrandin II (T-II), a hydrolysable tannin, could be explained by the availability of either light or nitrogen. However, the pool of phenolic compounds reacted differently than the individual compound T-II.

The major questions asked in this study were: Does the carbon-nutrient balance hypothesis $(\mathrm{CNBH}$; Bryant 
et al. 1983) explain intraspecific differences in the pool of $M$. spicatum phenolic compounds? And does T-II respond in a similar way to resource variations? Considering the wide allelochemical activity of T-II, phenotypic variation of this metabolite could also be a response to varying biotic stressors such as herbivores or competing photoautotrophs, i.e. supporting the optimal defence model (ODM; Rhoades 1979, Karban and Myers 1989).

Light strongly influenced the amount of phenolic compounds in $M$. spicatum. Higher light levels triggered both an increase of tissue-bound and exuded phenolic compounds $\left(\mathrm{TPC}_{\mathrm{t}}, \mathrm{TPC}_{\mathrm{e}}\right)$. To what extend exuded phenolic compounds contribute to the total secondary metabolite pool is difficult to assess; in our study $\mathrm{TPC}_{\mathrm{e}}$ during two weeks contributed only about $1 \%$ to $\mathrm{TPC}_{\mathrm{t}}$. Nevertheless, $\mathrm{TPC}_{\mathrm{e}}$ from $M$. spicatum are allelopathically active, inhibiting for example alkaline phosphatase activity of cyanobacteria and algae (Gross et al. 1996). In milfoil, higher tissue levels of $\mathrm{TPC}_{t}$ and an increased exudation of TOC and $\mathrm{TPC}_{\mathrm{e}}$ under high light possibly reflect physiological constraints and represent sinks for surplus carbon. Aquatic primary producers generally exude significant amounts of organic carbon during times of high photosynthetic activity (Wetzel 2001). These observations are in accordance with the $\mathrm{CNBH}$.

In low light, the TOC consisted of a higher proportion of phenolic compounds $\left(\mathrm{TPC}_{\mathrm{e}}\right)$ compared to high light treatments. This relative, but not absolute change in exudation of allelopathically active compounds may be advantageous for milfoil subjected to shading by competing phytoplankton or epiphytes. These findings do not support the CNBH.

Nitrogen availability did not influence $\mathrm{TPC}_{\mathrm{t}}, \mathrm{TPC}_{\mathrm{e}}$ or TOC. The nitrogen content $(2.2-3.7 \%[\mathrm{w} / \mathrm{w}] ;$ mean $=$ $3.0 \%)$ and $\mathrm{C}: \mathrm{N}$ ratios $(9.0-15.9$; mean $=12.4)$ in axenic $M$. spicatum were well within the range found in field milfoil by Spencer and Ksander $(1999 ; 1.3-4.8 \% \mathrm{~N}$; mean 2.8\%; 8.3-18.9 C:N ratio; mean 12.7). Some authors, however, reported in situ nitrogen limitation of Myriophyllum aquaticum (Sytsma and Anderson 1993b) and M. spicatum (Gerloff 1975). The nitrate concentration in medium offered to axenic $M$. spicatum was always above limiting conditions (Sytsma and Anderson 1993a) and may have prevented a stronger impact of this resource on CBSC as predicted by the $\mathrm{CNBH}$. Confirmation for the validity of our findings emerge from our investigations on M. spicatum in Lake Constance (E. M. Gross, unpubl.): Preliminary results indicate that these plants exhibit a significant negative correlation between nitrogen content and content of polyphenols (both $\mathrm{TPC}_{\mathrm{t}}$ and T-II). Comparable results were obtained in the laboratory with non-axenic shoots grown under varying nitrogen supply at controlled conditions. Lake plants had frequently high $\mathrm{C}: \mathrm{N}$ ratios, ranging from $8: 1$ to $35: 1$, depending on plant part (meristem, leaves, stems) and date. The present study showed that light influences the nitrogen acquisition in axenic plants. Thus, light could influence polyphenol concentration either directly depending on light availability, determined by changes in water turbidity, water level or weather conditions, or indirectly via nitrogen acquisition. For that reason, the impact of light on polyphenols is difficult to asses under field conditions. In $M$. spicatum from Lake Constance, light also positively influenced TPC when water level as a surrogate for light availability was used (E. M. Gross, unpubl.).

Phenolic compounds in M. spicatum are predominantly hydrolysable tannins (HT; Gross et al. 1996). The findings of this study on the impact of light and nitrogen on HT are in accordance with a meta-analysis by Koricheva et al. (1998) where nitrogen had no clear effect on the level of HT and only shading (i.e. light) caused a strong decline. In comparison, the metaanalysis revealed that phenylalanine-derived CBSC declined both at low light and high nitrogen availability. The current notion is that this divergence originates from different biosynthetic pathways. The biosynthesis of most HT occurs not via phenylalanine but directly from shikimate (Seigler 1998). Gross (1992) stated that although the shikimate-derived pathway is probably most widespread among plants, another biosynthetic pathway via phenylalanine/cinnamic acid exists and is realized in some plants. Unfortunately not much is known about the systematic distribution of these biosynthetic pathways, and nothing is known about gallic acid biosynthesis in $M$. spicatum. The negligible impact of nitrate on HT in M. spicatum suggests that HT might be synthesized via shikimate.

Light and nitrogen acted differently on T-II than on the total phenolics in axenic milfoil. Only a moderate impact of light on T-II in M. spicatum was apparent. In contrast to $\mathrm{TPC}_{\mathrm{t}}$ and $\mathrm{TPC}_{\mathrm{e}}$, nitrogen had an impact on T-II content. Then, when T-II concentrations were correlated with tissue $\mathrm{C}: \mathrm{N}$ ratios that integrate the actual amount of carbon and nitrogen allocated during plant growth at different light and nitrogen levels, the effect of light was eliminated, and T-II concentrations increased with growing tissue $\mathrm{C}: \mathrm{N}$ ratios. Thus, the distinct difference between the reaction of the total phenolic compounds and T-II in M. spicatum towards different light and nitrogen levels cannot be explained by the CNBH.

Koricheva et al. (1998) proposed that CBSC are determined both by resource availability and specific demand-site responses, and that these mechanisms work at different hierarchical levels. The higher hierarchical level predicts the total amount of carbon that can be allocated to CBSC, and would be supported by the $\mathrm{CNBH}$. However, at the lower hierarchical level, predicting changes in individual CBSC would demand more insight into biosynthetic pathways and environmental constraints of the plant. Bryant et al. (1987) 
already asked whether the availability of carbon and nutrients directly determine the content of CBSC or indirectly via enzymes regulating secondary metabolites. The results of this study substantiate the requirement for a better knowledge on biosynthesis and regulation of individual secondary metabolites.

Previous results indicate the adaptive value of increased concentrations of TPC and T-II both in the interaction of $M$. spicatum with photoautotrophs and with insect herbivores. M. spicatum polyphenols, especially T-II, interfere with photosystem II (Leu et al. 2002). Inhibition of photosynthesis by allelopathically active compounds from aquatic photoautotrophs is apparently widespread and is an effective mechanism in the competition with other primary producers for light and other resources (Gross 2003). The higher concentration of T-II in the low light level, both absolute and relative to the $\mathrm{TPC}_{\mathrm{t}}$, indicates that $M$. spicatum may produce high amounts of this major allelochemical even when epiphytes and phytoplankton cause shading. The same polyphenols are active in the interaction of $M$. spicatum with insect herbivores. Growth of larvae of the aquatic moth Acentria ephemerella was reduced when they fed on $M$. spicatum containing high levels of polyphenols (Choi et al. 2002). The major active compound interfering with gut symbiotic bacteria in Acentria, was T-II (Walenciak et al. 2002). Whether the antimicrobial activity of milfoil polyphenols is the primary reason for the reduced growth of this herbivore is, however, not yet clear.

Thus, hydrolysable tannins exhibit multiple functions in $M$. spicatum and allow the plant to respond to different abiotic and biotic stressors. Furthermore, $M$. spicatum polyphenols may additionally serve as antioxidants or for UV protection. The latter may be important because this species typically grows to the water-surface, forming canopies. Sun-exposed shoots and especially apical meristems tend to have higher concentrations of T-II and $\mathrm{TPC}_{t}$ than shade adapted plants (Choi et al. 2002, E. M. Gross, unpubl.). The biosynthetic pathways by which $M$. spicatum regulates the shift towards more T-II among TPC $_{t}$ when light is limited remains unclear. Accumulation of high concentrations of polyphenols during clear water phases and profiting from these resources under more turbid conditions might be an adaptive strategy, but this scenario would strongly depend on growth rate and the presently unknown turnover times of polyphenols.

These results imply that individual compounds are as and maybe more important to the success of a plant as is the pool of CBSC. Single active compounds are generally regarded of higher adaptive value for a plant than the pool of a specific class of secondary compounds (Berenbaum 1995). The question remains if and how $M$. spicatum regulates the production of individual HT and the pool of HT in view of the multiple defensive functions that these allelochemicals have. Respond- ing to a single factor might be disadvantageous with regard to other threats. It is conceivable that this submersed macrophyte uses resources, especially light, as a proximate factor to react to biotic stressors, especially competing photoautotrophs. This would explain the observations of this study. To explain the regulation of T-II, more insight both into biosynthetic pathways of HT and the impact of combined stressors on $M$. spicatum allelochemicals is needed. In conclusion, the results presented here underline the need for a revised view of the $\mathrm{CNBH}$. Explaining the divergence in the reaction of total phenolic compounds and individual compounds towards resource availability and biotic stressors by different hierarchial levels (Koricheva et al. 1998) seems, in my opinion, a reasonable starting point to reassess factors influencing the intraspecific variability of CBSC in plants.

Acknowledgements - Deutsche Forschungsgemeinschaft (SFB 454, TP A2) and the Max-Planck Society supported this work in part. Dietmar Lemcke measured the carbon and nitrogen content, Dieter Albrecht measured TOC. Daniel Baumgärtner provided statistical advice and Alene Onion improved the English of the manuscript. A previous version of this manuscript benefited from valuable comments by John P. Bryant.

\section{References}

Abernethy, V. J., Sabbatini, M. R. and Murphy, K. J. 1996. Response of Elodea canadensis Michx. and Myriophyllum spicatum L. to shade, cutting and competition in experimental culture. - Hydrobiologia 340: 219-224.

Barko, J. W. and Smart, R. M. 1981. Comparative influence of light and temperature on the growth and metabolism of selected submersed freshwater macrophytes. - Ecol. Monogr. 51: 219-235.

Berenbaum, M. R. 1995. The chemistry of defense: theory and practice. - PNAS 92: 2-8

Bryant, J. P., Chapin III, F. S. and Klein, D. R. 1983. Carbon/nutrient balance of boreal plants in relation to vertebrate herbivory. - Oikos 40: 357-368.

Bryant, J. P., Chapin III, F. S., Reichardt, P. B. et al. 1987. Response of winter chemical defense in Alaska paper birch and green alder to manipulation of plant carbon-nutrient balance. - Oecologia 72: 510-514.

Choi, C., Bareiss, C., Walenciak, O. et al. 2002. Impact of polyphenols on the growth of the aquatic herbivore Acentria ephemerella (Lepidoptera: Pyralidae). - J. Chem. Ecol. 28: $2245-2256$.

Fikenscher, L. H. and Hegnauer, R. 1981. Die Verbreitung der Blausäure bei den Cormophyten. 16. Mitteilung über Cyanogenese bei den Haloragaceae. - J. Nat. Prod. 44: $705-712$.

Gerloff, G. C. 1975. Nutritional ecology of nuisance aquatic plants. - U.S. Environmental Protection Agency/EPA. Washington, DC, USA. Ecological Research Series. EPA660/3-75-027. $78 \mathrm{pp}$.

Gerloff, G. C. and Krombholz, P. H. 1966. Tissue analysis as a measure of nutrient availability for the growth of angiosperm aquatic plants. - Limnol. Oceanogr. 11: 529537.

Gross, E. M. 2003. Allelopathy of aquatic autotrophs. - Crit. Rev. Plant Sci. 22: 313-339.

Gross, E. M. and Sütfeld, R. 1994. Polyphenols with algicidal activity in the submerged macrophyte Myriophyllum spicatum L. - Acta Horticul. 381: 710-716. 
Gross, E. M., Meyer, H. and Schilling, G. 1996. Release and ecological impact of algicidal hydrolyzable polyphenols in Myriophyllum spicatum. - Phytochemistry 41: 133-138.

Gross, G. G. 1992. Enzymes in the biosynthesis of hydrolyzable tannins. - In: Hemingway, R. W. and Laks, P. E. (eds), Plant polyphenols: synthesis, properties, significance. Plenum Press, pp. 43-60.

Hamilton, J. G., Zangerl, A. R., DeLucia, E. H. et al. 2001 The carbon-nutrient balance hypothesis: its rise and fall. Ecol. Lett. 4: 86-95.

Kane, M. E. and Gilman, E. F. 1991. In vitro propagation and bioassay systems for evaluating growth regulator effects on Myriophyllum species. - J. Aquat. Plant Manage. 29: 29-32.

Kane, M. E., Gilman, E. F. and Jenks, M. A. 1991. Regenerative capacity of Myriophyllum aquaticum tissues cultured in vitro. - J. Aquat. Plant Manage. 29: 102-109.

Karban, R. and Myers, J. H. 1989. Induced plant responses to herbivory. - Annu. Rev. Ecol. Sys. 20: 331-348.

Koricheva, J. 2002. The carbon-nutrient balance hypothesis is dead: long live the carbon-nutrient balance hypothesis? Oikos7 98: 537-539.

Koricheva, J., Larsson, S., Haukioja, E. et al. 1998. Regulation of woody plant secondary metabolism by resource availability: hypothesis testing by means of meta-analysis - Oikos 83: 212-226.

Lerdau, M. and Coley, P. D. 2002. Benefits of the carbonnutrient balance hypothesis. - Oikos 98: 534-536.

Leu, E., Krieger-Liszkay, A., Goussias, C. et al. 2002. Polyphenolic allelochemicals from the aquatic angiosperm Myriophyllum spicatum L. inhibit photosystem II. - Plant Physiol. 130: 2011-2018.

Madsen, J. D., Hartleb, C. F. and Boylen, C. W. 1991 Photosynthetic characteristics of Myriophyllum spicatum and six submersed aquatic macrophyte species native to Lake George, New York. - Freshw. Biol. 26: 233-240.

Murashige, T. and Skoog, F. 1962. A revised method for rapid growth bioassays with tobacco tissue cultures. - Physiol Plant. 15: 473-497.

Nitao, J. K., Zangerl, A. R., Berenbaum, M. R. et al. 2002 CNB: requiescat in pace? - Oikos 98: 540-546.
Ostrofsky, M. L. and Zettler, E. R. 1986. Chemical defences in aquatic plants. - J. Ecol. 74: 279-287.

Pavia, H. and Brock, E. 2000. Extrinsic factors influencing phlorotannin production in the brown alga Ascophyllum nodosum. - Mar. Ecol. Progr. Ser. 193: 285-294.

Rhoades, D. F. 1979. Evolution of plant chemical defense against herbivores. - In: Rosenthal, G. A. and Janzen, D. H. (eds), Herbivores: their interaction with secondary plant metabolites. Academic Press, pp. 3-54.

Sand-Jensen, K. 1990. Epiphyte shading - its role in resulting depth distribution of submerged aquatic macrophytes. Fol. Geobot. Phytotax. 25: 315-320.

Schultz, J. C., Hunter, M. D. and Appel, H. M. 1992. Antimicrobial activity of polyphenols mediates plant-herbivore interactions. - In: Hemingway, R. W. and Laks, P. E. (eds), Plant polyphenols: synthesis, properties, significance. Plenum Press, pp. 621-638.

Seigler, D. S. 1998. Plant secondary metabolism. - Kluwer Academic Publishers.

Smolders, A. J. P., Vergeer, L. H. T., van der Velde, G. et al. 2000. Phenolic contents of submerged, emergent and floating leaves of aquatic and semi-aquatic macrophyte species: why do they differ? - Oikos 91: 307-310.

Spencer, D. F. and Ksander, G. G. 1999. Phenolic acids and nutrient content for aquatic macrophytes from Fall River, California. - J. Freshwater Ecol. 14: 197-209.

Sytsma, M. D. and Anderson, L. W. J. 1993a. Criteria for assessing nitrogen and phosphorus deficiency in Myriophyllum aquaticum. - J. Freshwater Ecol. 8: 155-163.

Sytsma, M. D. and Anderson, L. W. J. 1993b. Nutrient limitation in Myriophyllum aquaticum. - J. Freshwater Ecol. 8: 165-176.

Van Alstyne, K. L. and Pelletreau, K. N. 2000. Effects of nutrient enrichment on growth and phlorotannin production in Fucus gardneri embryos. - Mar. Ecol. Progr. Ser 206: $33-43$.

Walenciak, O., Zwisler, W. and Gross, E. M. 2002. Influence of Myriophyllum spicatum derived tannins on gut microbiota of its herbivore Acentria ephemerella (Lepidoptera: Pyralidae). - J. Chem. Ecol. 28: 2045-2056.

Wetzel, R. G. 2001. Limnology - lakes and river ecosystems, 3rd ed. - Academic Press, p. 510. 